\title{
Microstrcutural Stability of Nanostructured Ferritic Alloys (NFA)
}

\author{
Reza Sharghi-Moshtaghin ${ }^{1}$, Shenyan Huang ${ }^{1}$, Richard DiDomizio $^{1}$, Laura Dial ${ }^{1}$ \\ 1.GE Global Research Center, 1 Research Circle, Niskayuna, NY 12309
}

\begin{abstract}
Nanostructured ferritic alloys (NFA), are being developed for various high temperature applications where mechanical strength including creep properties and good resistance to irradiation damage is desired [1,2]. NFAs with a high chromium content $(\mathrm{Cr}>12 \%)$ present a fully ferritic matrix and are envisaged for applications in an extended range of temperature [3]. The high temperature strength is achieved by fine, homogeneously distributed nanoclusters in a ductile matrix that play an important role in enhancing mechanical strength [4]. The balance of chemical composition and most importantly $\mathrm{Cr}$ in these alloys is critical in order to maintain a ferritic structure and achieve desired corrosion and oxidation properties. However during thermal exposure at higher temperature and $\mathrm{Cr}$ levels due to phase stability or phase separation, high temperature $\alpha$-BCC may transform into iron rich (BCC) and $\alpha^{\prime}-\mathrm{Cr}$ (BCC) phases. This phase transformation could change corrosion and/or mechanical properties of the alloy and affect performance of the material.
\end{abstract}

In this study an NFA was prepared via a mechanical alloying process and subsequent hot consolidation, the detail of processing has been discussed elsewhere [5]. The chemical composition of the alloy used in this study is given in table 1 . The billet was cut into pieces and aged at $427^{\circ} \mathrm{C}\left(800^{\circ} \mathrm{F}\right), 482^{\circ} \mathrm{C}\left(900^{\circ} \mathrm{F}\right)$ and $537^{\circ} \mathrm{C}\left(1000^{\circ} \mathrm{F}\right)$ up to $25,000 \mathrm{hrs}$. Each aged sample was removed from the furnace at a specific time interval and mechanical properties including Vickers hardness and tensile properties were measured. Microstructural evaluation on each sample was carried out using a 200KV Tecni-Osiris TEM equipped with 4 EDS detectors.

TEM results showed that phase separation leads to the formation of the chromium-rich $\alpha^{\prime}$ phase (Fig1,2). Also a tungsten rich laves phase was found at the grain boundaries after $2500 \mathrm{hrs}$ exposure at $482^{\circ} \mathrm{C}$ (Fig.2). Experimental results showed that tensile properties of the alloy are not significantly affected by annealing time (Fig. 3). This behavior is attributed to dislocation/NFA interaction and is under investigation.

Reference:

[1] G.R. Odette, JOM, Vol.66, No 12 (2014) 2427-2441

[2] M.L. Hamilton, et al., Fabrication Technique for ODS alloy MA957, Report PNL-13165, 2000

[3] A. Alamo et al., J. Nuc. Mater, Vol. 329-333, (2004) 338-341

[4] J.H. Ahh, S. Lee and J Jang, Advanced Materials Research Vols. 15-17 (2007) 696-701

[5] R. DiDomizio, S. Huang, L. Dial and M. Larsen, Met. Trans. A, Vol54A (2014) 5409-5418 
Table 1. Chemical composition of the ODS alloy used in this study (wt\%)

\begin{tabular}{|c|c|c|c|c|c|c|}
\hline Alloy & Fe & Cr & W & Ti & Y2O3 & B \\
\hline NFA1 & Bal. & 14 & 3 & 1.2 & 0.75 & - \\
\hline NFA2 & Bal. & 14 & 3 & 0.8 & 0.5 & 0.03 \\
\hline
\end{tabular}
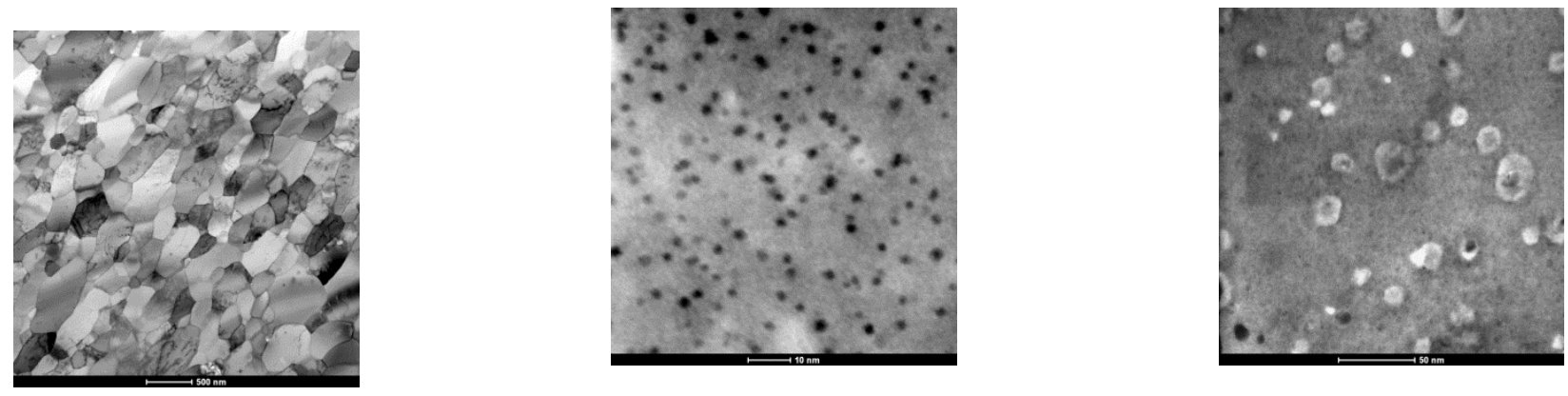

Figure 1. a- general microstructure shows the grain size of the alloy; b-STEM BF image shows 2-5 nm Nanoclusters formed in the microstructure in as-received condition, $\mathrm{c}-\alpha^{\prime} \mathrm{Cr}$ particles formed in the microstructure after aging at $482^{\circ} \mathrm{C}\left(900^{\circ} \mathrm{F}\right)$ for $10000 \mathrm{hrs}$.
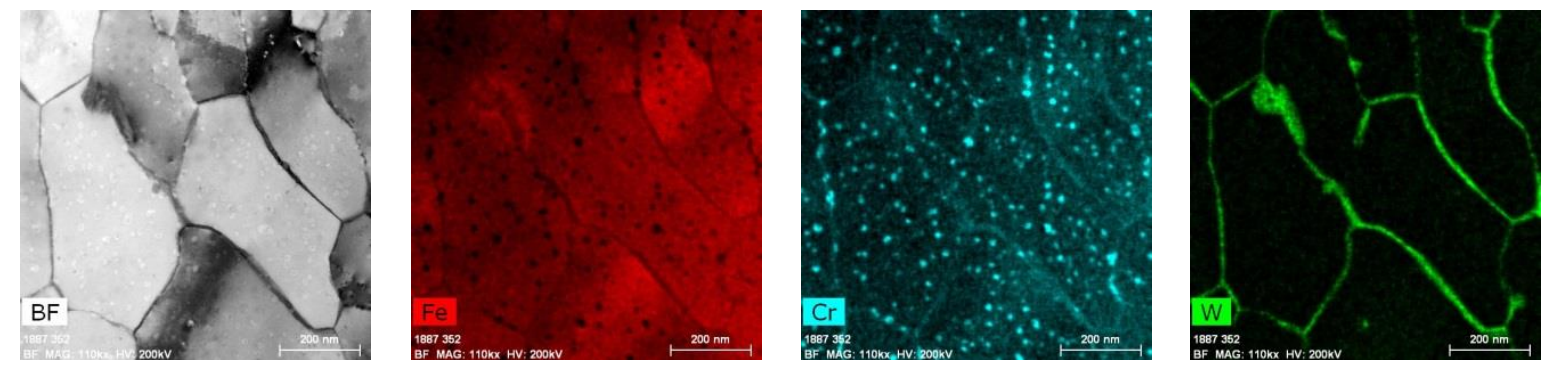

Figure 2. EDS elemental map show formation of $\alpha^{\prime} \mathrm{Cr}$ and Laves phsase in the microstructure after aging the sample at $482^{\circ} \mathrm{C}\left(900^{\circ} \mathrm{F}\right)$ for $10000 \mathrm{hrs}$.
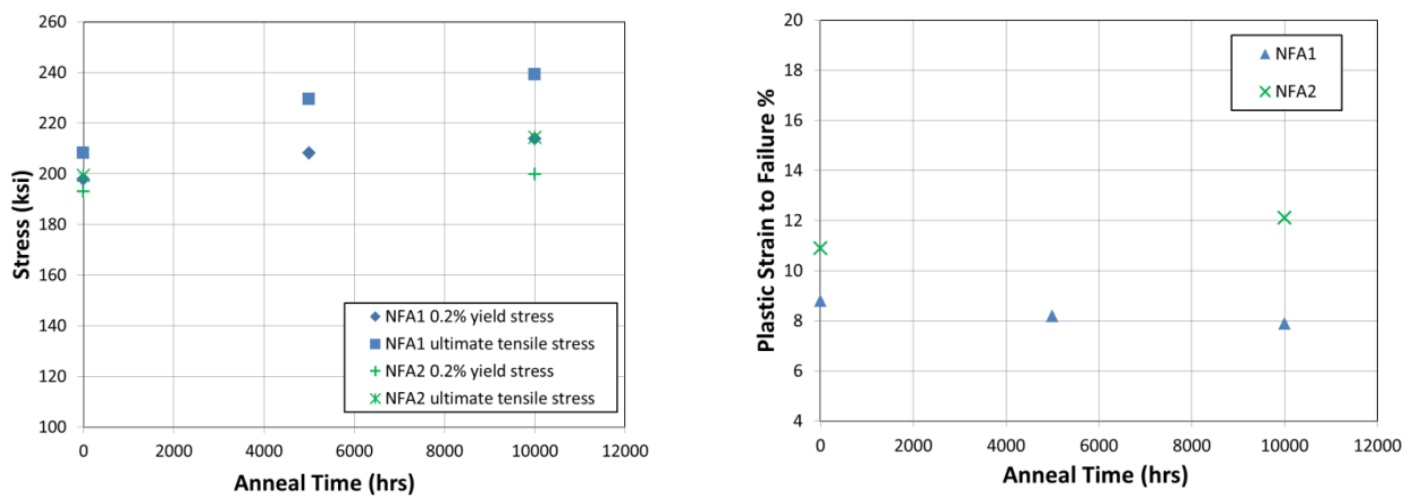

Figure 3. Room temperature $0.2 \%$ yield stress and ultimate tensile stress and (b) plastic strain to failure for two NFAs as a function of anneal time at $900 \mathrm{~F}$. 